\title{
Editorial
}

EDITORIAL DA presente edição da revista MATRIZes, edição de número

8.2, em oito anos de publicação ininterrupta, inicia-se com a citação de um pequeno trecho do canto XXIV do poema $\mathbf{O}$ Guardador de Rebanhos, de Alberto Caeiro, o heterônimo de Fernando Pessoa mais voltado para a abordagem da visão e da realidade:

O essencial é saber ver,

(...)

Mas isso (triste de nós que trazemos a alma vestida!)

Isso exige um estudo profundo,

Uma aprendizagem de desaprender.

(...)

No Dossiê, para poder enxergar constantes, compreender sentidos e interpretar vetores no mundo que nos cerca é preciso saber ver para além da multiplicidade das aparências e renovar o olhar pela aprendizagem de novas óticas. É preciso um olhar renovado para que se possa compreender o novo tipo de relação do Estado, no que tange à cultura e à tecnologia, nas interações entre comunidades locais e atores mundiais - como faz Jesús Martín-Barbero, no artigo Diversidade em convergência. Igualmente, Margarida M. Krohling Kunsch em Comunicação Organizacional: contextos, paradigmas e abrangência conceitual exemplifica como o suporte teórico-conceitual é constituinte de olhares renovadores sobre objetos e realidades conhecidas.

Visões dicotômicas simples sobre a mídia e o mundo midiatizado como lugar da mercantilização da cultura ou ainda sobre o papel da tecnologia nos processos comunicacionais não dão conta da complexidade da realidade comunicativa atual. 
Depois de apresentar criticamente algumas teorias dominantes no pensamento comunicacional das décadas de 1970 e 1980, Vera França em Crítica e metacrítica: contribuição e responsabilidade das teorias da comunicação traz o debate para o momento atual e destaca a complexidade dos produtos midiáticos por serem produtos simbólicos repletos de tensões.

A etnometodologia do discurso, como nova proposta divergente da chamada análise do discurso por propor o privilégio da dimensão pragmática dos fenômenos de produção discursiva, é apresentada por Adriano Duarte Rodrigues e Adriana Andrade Braga no artigo Análises do discurso e abordagem etnometodológica do discurso.

Ainda sobre o tópico de romper fronteiras para construir novos olhares e novos conhecimentos, Raúl Fuentes Navarro, no artigo Comunicação e dupla hermenêutica: convergências entre disciplinas científicas e profissões, nos fala sobre as "autossimilaridades que permitem definir e distinguir entre si, sem dissociá-las, as estruturas disciplinares (científico-acadêmicas) e as profissionais que têm a comunicação como objeto principal”.

Fechando o Dossiê, com A transnacionalização de programas televisivos na região ibero-americana, John Sinclair retoma aspectos presentes no artigo de Jesús Martín-Barbero de como repensar noções como as de imperialismo cultural ou cultura global, relacionadas a supostas tendências de homogeneização da globalização cultural, e os efeitos heterogeneizadores da cultura local.

Comunidades locais, atores mundiais; culturas homogeneizadas globais, culturas heterogeneizadas e específicas locais; o mundo que se integra e se fragmenta em novas associações - são os temas da entrevista com Daya Kishan Thussu, realizada por Andrea Medrado: O Ocidente, o "resto" do mundo e a internacionalização dos Estudos de Mídia - “Chíndia”, BRICS e soft power.

Oito artigos compõem a seção Em Pauta deste número de MATRIZes. Dois artigos analisam produções da cultura impressa brasileira: Waldomiro Vergueiro e Roberto Elísio dos Santos resgatam e apresentam uma revista publicada no final da década de 1930: A revista Gibi e a consolidação do mercado editorial de quadrinhos no Brasil. Figura importantíssima para a consolidação da indústria do livro no Brasil, a produção jornalística de Monteiro Lobato é analisada por Francisco de Assis no artigo Monteiro Lobato na imprensa.

Ainda no âmbito da palavra escrita, mas transmitida digitalmente, estão dois artigos. O primeiro, Perdidos na tradução: Grau 26 e a literatura digital interativa, de Marina Cavalcanti Tedesco e Pedro Peixoto Curi, trata de um romance digital interativo integrando a leitura em papel, as redes sociais e narrativas microcurtas. E o segundo, Narrativa e violência: a cobertura do Outono Brasileiro no Twitter, de Raquel Recuero, Marco Toledo Bastos e Gabriela Zago, apresenta o resultado do 
monitoramento de quase 3.000 tweets de dez veículos jornalísticos brasileiros na cobertura dos protestos de junho de 2013 no Brasil, através do qual comparam os dados obtidos com os dados oficiais sobre mortos, feridos e presos em 268 protestos ocorridos no período.

A biografia do ponto de vista comunicacional é o título do artigo de Igor Sacramento que desenvolve a noção de biografia comunicacional, cujo foco "não recai sobre a atividade individual, mas sobre o circuito comunicativo das produções discursivas imbricadas num indivíduo”. No mesmo âmbito temático, Samuel Mateus no artigo Regimes de visibilidade na publicidade mediatizada indica como a esfera pública em um contexto de midiatização é um espaço de negociação entre o público e o privado.

As especificidades da audiência televisiva chilena são enfocadas por William Porath, Constanza Mujica e Francisco Maldonado Ulloa no artigo Fatores associados com o interesse do público chileno por notícias estrangeiras na TV, em que concluem que a proximidade sentida pelo público é fator determinante na audiência, de temas da política externa, que cresce quando a notícia é vinculada com o contexto local.

A complexidade do filósofo Walter Benjamin aparece no texto de Maurício Liesen, $\mathbf{O}$ medium silenciado: re-flexões teórico-comunicacionais sobre uma teoria dos media em Walter Benjamin, que aborda especificamente seu texto sobre a linguagem geral e linguagem humana, escrito em 1916.

Encerrando o presente volume, o leitor encontrará na seção Resenhas dois artigos sobre livros recentemente lançados: Contra a barbárie da incomunicação e pela construção de uma sociedade educativa, de Roberta Brandalise e Sandro Assencio, que traz a resenha do livro de Jesús Martín-Barbero, A comunicação na educação, e explica as formas como esse autor trabalha os atuais processos de alfabetização comunicativa em seus diferentes suportes materiais e como essa nova alfabetização constrói novas interfaces com a cultura e impõe desafios à escola e à escrita.

Silvia Roca Baamonde, no texto Identidade, cinema e diversidade: dialéticas frente a convergência digital, apresenta uma síntese do livro coordenado por Margarita Ledo Andión Cine, diversidade y redes. Pequeñas cinematografías, políticas de la diversidad y nuevos modos de consumo cultural que se propõe a pensar e analisar estratégias para superar a marginalidade do cinema de culturas/ línguas minorizadas e sobreviver em um mercado globalizado e monopolizado pelas grandes distribuidoras multinacionais. Mais uma vez, a questão da especificidade das culturas locais se coloca como um tema central na comunicação contemporânea.

$$
* * *
$$


1. Ver: $<$ http://scholar. google.com.br/ citations?view_op=top_ venues\&hl $=$ en\&vq=pt $>$. Acesso em 16 de nov. 2014.
O Comitê Editorial tem feito esforços para manter MATRIZes atualizada com o estado da arte da publicação científica. Um dos temas mais debatidos hoje é a ética na publicação. Temos buscado literatura pertinente ao assunto (CNPq, 2011; FAPESP, 2014 e Coury, 2012) de modo a apoiar e fundamentar decisões da Revista. Com isso, pretendemos divulgar posicionamentos sobre o tema a partir de 2015 .

Permitimo-nos fazer duas referências a respeito da repercussão de MATRIZes. A primeira, por aparecer classificada entre as cem revistas de Língua Portuguesa com melhor índice h5, conforme o Google Scholar ${ }^{1}$. E a segunda, por reaparecer com a melhor posição na área da Comunicação do Brasil no ranking elaborado por Repiso e López (2013).

Finalmente, o balanço parcial do ano (a ser completado no primeiro volume de 2015), registra que MATRIZes teve um número elevado de submissões: foram mais de 60 textos, entre artigos e resenhas. A par disso, queremos ressaltar o importante papel dos pareceristas, que garantem a qualidade da revista, a quem expressamos um especial agradecimento. $\mathbf{M}$

\section{PARECERISTAS DE 2014}

Adair Caetano Peruzzolo - Universidade Federal de Santa Maria, Brasil Alberto Efendy Maldonado - Universidade do Vale do Rio dos Sinos, Brasil Alfredo Suppia - Universidade Estadual de Campinas, Brasil Ana Carolina Escosteguy - Pontifícia Universidade Católica do Rio Grande do Sul, Brasil Ana Cláudia Gruszynski - Universidade Federal do Rio Grande do Sul, Brasil Ângela Prysthon - Universidade Federal de Pernambuco, Brasil

Barbara Heller - Universidade Paulista, Brasil

Carlos Gerbase - Pontifícia Universidade Católica do Rio Grande do Sul, Brasil

Catarina Burnay - Universidade Católica Portuguesa, Portugal

Cláudia Irene de Quadros - Universidade Federal do Paraná, Brasil

Cláudia Peixoto de Moura - Pontifícia Universidade Católica do Rio Grande do Sul, Brasil

Claudio Guimarães Cardoso - Universidade Federal da Bahia, Brasil

Clotilde Perez - Universidade de São Paulo, Brasil

Cristina Teixeira Melo - Universidade Federal de Pernambuco, Brasil

Eduardo Vicente - Universidade de São Paulo, Brasil

Fabrício Lopes da Silveira - Universidade do Vale do Rio dos Sinos, Brasil

Francisco Paulo Jamil Almeida Marques - Universidade Federal do Ceará, Brasil

Francisco Rüdiger - Pontifícia Universidade Católica do Rio Grande do Sul, Brasil

Gislene Silva - Universidade Federal de Santa Catarina, Brasil

Igor Sacramento - Universidade Federal do Rio de Janeiro, Brasil

Jairo Getúlio Ferreira - Universidade do Vale do Rio dos Sinos, Brasil

Jiani Adriana Bonin - Universidade do Vale do Rio dos Sinos, Brasil

João Carlos Massarolo - Universidade Federal de São Carlos, Brasil

José Luiz Aidar Prado - Pontifícia Universidade Católica de São Paulo, Brasil

Juremir Machado da Silva - Pontifícia Universidade Católica do Rio Grande do Sul, Brasil

Kati Eliana Caetano - Universidade Tuiuti do Paraná, Brasil 
Lucrécia D’Aléssio Ferrara - Pontifícia Universidade Católica de São Paulo, Brasil

Luis Mauro Sá Martino - Faculdade Cásper Líbero, Brasil

Luiz Alberto Farias - Universidade de São Paulo, Brasil

Luiz Signates - Universidade Federal de Goiás, Brasil

Marcelo Briseno Marques de Melo - Universidade Metodista de São Paulo, Brasil

Marco André Feldman Schneider - Universidade Federal Fluminense, Brasil

Marco Toledo Bastos - Duke University, EUA

Maria Lília Dias de Castro - Universidade Federal de Santa Maria, Brasil

Maurício Liesen - Universidade de São Paulo, Brasil

Mayra Rodrigues Gomes - Universidade de São Paulo, Brasil

Michael Manfred Hanke - Universidade Federal do Rio Grande do Norte, Brasil

Nina Velazco e Cruz - Universidade Federal de Pernambuco, Brasil

Paulo Roberto Nassar - Universidade de São Paulo, Brasil

Raúl Fuentes Navarro - Universidad Jesuita de Guadalajara, México

Regina Lucia Gomes - Universidade Federal da Bahia, Brasil

Richard Romancini - Universidade de São Paulo, Brasil

Rogério Christofoletti - Universidade Federal de Santa Catarina, Brasil

Rosana Soares - Universidade de São Paulo, Brasil

Rosane Rosa - Universidade Federal de Santa Maria, Brasil

Sandra Portella Montardo - Universidade Feevale, Brasil

Sandra Reimão - Universidade de São Paulo, Brasil

Sandra Ribeiro de Souza - Universidade de São Paulo, Brasil

Simone Rocha - Universidade Federal de Minas Gerais, Brasil

Suely Fragoso - Universidade Federal do Rio Grande do Sul, Brasil

Thiago Soares - Universidade Federal de Pernambuco, Brasil

Valquiria Aparecida Passos Kneipp - Universidade Federal do Rio Grande do Norte, Brasil

Veneza Ronsini - Universidade Federal de Santa Maria, Brasil

Walter Teixeira Lima Junior - Universidade Metodista de São Paulo, Brasil

\section{REFERÊNCIAS}

CNPq. Relatório da Comissão de Integridade de Pesquisa do CNPq. Brasília: CNPq, 2011. Disponível em <http://www.cnpq.br/documents/10157/a8927840-2b8f-43b9-8962-5a2ccfa74dda>. Acesso em 16 de nov. 2014.

COURY, Helenice J. C. G. Integridade na pesquisa e publicação científica. Rev. bras. fisioter., São Carlos, v. 16, n. 1, fev. 2012. DOI: http://dx.doi.org/10.159o/S1413-35552012000100001

FAPESP. Código de Boas Práticas Científicas, São Paulo: Fapesp, 2014. Disponível em <http:// www.fapesp.br/boaspraticas/FAPESP-Codigo_de_Boas_Praticas_Cientificas_2014.pdf >. Acesso em 16 de nov. 2014.

REPISO, Rafael; LÓPEZ CÓZAR, Emilio Delgado. H Index Communication Journals according to Google Scholar Metrics (2008-2013). EC3 Reports, v. 10, n. 24, 2013. Disponível em <http:// www.revistacomunicar.com/pdf/2014-gsm-2009-2013.pdf>. Acesso em 16 de nov. 2014.

Maria Immacolata Vassallo de Lopes

Sandra Reimão

Richard Romancini 